\title{
V. An examination of women's professional visibility in cognitive psychology
}

\section{Jyotsna Vaid and Lisa Geraci}

Texas A\&M University, USA

\begin{abstract}
Mainstream psychological research has been characterized as androcentric in its construction of males as the norm. Does an androcentric bias also characterize the professional visibility of psychologists? We examined this issue for cognitive psychology, where the gender distribution in doctoral degrees has been roughly equal for several decades. Our investigation revealed that, across all indicators surveyed, male cognitive psychologists are more visible than their female counterparts: they are over-represented in professional society governance, as editors-in-chief of leading journals in the field, as Fellows in professional societies, and as recipients of prestigious senior level awards. Taken together, our findings indicate that a gender parity in doctoral degrees in cognitive psychology does not translate into a parity in professional visibility. We discuss a variety of potential reasons for the observed gender gap and suggest that, without attention to gendered structures of status and power, as noted by Shields, existing gender hierarchies may persist and be reproduced.
\end{abstract}

\section{Keywords}

androcentrism, professional visibility, women in academia, gender gap, cognitive psychology

In her seminal article in 1975, Stephanie Shields discussed various manifestations of an androcentric bias that has shaped research in psychology from its very beginnings. Other dominant, biasing frames in mainstream psychological research have since been identified, including heterosexism (Braun, 2000), cisgenderism (Ansara

\section{Corresponding author:}

Jyotsna Vaid, Department of Psychology, Texas A\&M University, College Station, TX 77843-4235, USA.

Email: jvaid@tamu.edu 
\& Hegarty, 2014), whiteness (Cundiff, 2012; Morawski, 2004; Salters \& Adams, 2013), and monolingualism (Vaid \& Meuter, 2016). For researchers in cognitive psychology (and in experimental psychology more generally), these biases have largely escaped notice because of a prevailing and largely unexamined belief (one may call it an "autonomous mind bias") that while one's lived experiences may shape the content of one's mental representations, they do not affect mental processes or structures. Put differently, the autonomous mind bias considers that it is both appropriate and sufficient to study an individual's cognitive processes and mental representations independently of the social, cultural, linguistic, or historical contexts in which individuals live. Indeed, the view that attention, perception, language, memory, or reasoning can be theorized without considering the influence of social/contextual processes (of which gender is one example) undergirds how cognitive psychology has constructed its subject matter and methods (see Fine \& Gordon, 1989; Morawski \& Agronick, 1991; Riger, 1992; Shields \& Dicicco, 2011; Weisstein, 1993, for further discussion).

Our article asks the following question: How might social/contextual processes such as gender affect not only the framing of topics or the choice of methods in a discipline but also the ways in which the scientific research enterprise itself functions, particularly in terms of the structures and procedures for determining and rewarding meritorious scholarship? We consider this question in the context of cognitive psychology but we believe this question is of relevance to the broader issue of the slow pace of women's professional advancement in academia (Valian, 1998).

The issue of women's professional visibility in cognitive psychology has received remarkably little attention. At the same time, this inattention to gender may not be that surprising given the field's focus on mental structures and processes and a broader belief in meritocracy, according to which one's professional visibility should not be influenced by such things as gender or race. Yet, treating one's social location as irrelevant to the study and practice of cognitive psychology may have consequences, for, as Morawski and Agronick (1991, p. 576) note, "emphasis on the "mental' underestimates the significance of the material, which includes concrete resources, institutional structures, historical alterations, and physical bodies."

However, conceptualizing gender as a potential source of difference at the level of the individual, that is, as a difference in abilities, including cognitive abilities (e.g., Miller \& Halpern, 2014), has its own problems. A gender-asdifference view, as Shields (2012) argues, constructs and reifies a rigid, twogender category system and often considers the mere presence of gender differences as sufficient explanation of phenomena rather than seeking to understand underlying contextual factors that may moderate any effects observed. Instead of conceptualizing gender as difference a more promising approach is viewing gender as context; this approach invites consideration of structural inequalities that are often masked when one seeks to locate differences within individuals (Shields, 2012, p. 431). 
In the present analysis, we take a gender-as-context approach to the study of knowledge production and professional recognition, for it is well established that science is conducted within a social context (e.g., Longino, 1990), and so exploring this context should offer insights into factors that affect a scientist's professional visibility. Previous investigations of this issue have examined whether women's growing presence in psychology at large has been accompanied by an increase in research by women, or in research topics that are female-centered, or by a growing number of women in leadership positions in the field (e.g., Kite et al., 2001; Eagly, Eaton, Rose, Riger, \& McHugh, 2012). While there have clearly been some of these changes, progress has been uneven. For example, an analysis of some 250 journal articles published in 2007 in eight different journals in psychology found that women were under-represented as senior authors (Cundiff, 2012). More recently, a gender disparity was noted in publication rates in top-ranked social psychology journals (Cikara, Rudman, \& Fiske, 2012). Our study seeks to extend this line of inquiry by examining a range of indicators of women's professional visibility in psychology particularly at senior levels and by focusing on the subfield of cognitive psychology.

Our decision to focus on cognitive psychology was motivated by the following reasons. One, we ourselves are trained in cognitive psychology and have been teaching, doing research, and reviewing journal articles in this subfield for many years, and can thus approach our investigation with the benefit of an insider's perspective and knowledge of this subfield, such as the major journals, professional organizations, and awards in cognitive psychology. We also bring to the project insights from our own lived experiences as senior scholars in academia with differing racialized identities. Two, training in cognitive psychology, more than in other subfields, is largely oriented to working in academic/research settings. Thus, we might expect that there should be less of a leaky pipeline issue for cognitive psychology doctorate holders than for those in other areas such as clinical or industrial/organizational psychology with faculty who have the option of working in other workplace settings outside of academia (for general discussion of the inadequacy of a pipeline framework, see Monroe \& Chiu, 2010). Since our goal was to examine how women fare in academic psychology, cognitive psychology is an appropriate subfield to examine. Whereas women comprised less than $2 \%$ of doctorates in experimental psychology in the period from 1920 to 1974 , there are currently roughly an equal number of men and women who earn their doctorate in cognitive/experimental psychology in the United States (Lazar \& Tuller, 2015). Moreover, this parity in doctorates has characterized the field for nearly 30 years. As noted in a 2006 report of the Women's Programs Office of the American Psychological Association (APA), in the subfield of cognitive psychology the proportion of women doctorates has hovered around 50\% (with some fluctuation in either direction) since 1990 (APA Women's Programs Office, 2006). Thus, all other things being equal, we would expect that men and women in cognitive psychology would come to assume positions of leadership and recognition to an equal degree. 
The question, of course, is whether all other things are equal. For example, we know that women are still not represented proportionally in the highest ranks in psychology. Despite the fact that the majority of PhDs in psychology in general are earned by women, women comprise only about $34 \%$ of full-time psychology faculty at the rank of full professor at research universities in the United States (APA Center for Workforce Studies, 2014). Although we do not have current data for psychologists in other countries, we expect that they are not likely to be that different than the US figures. For example, according to a 2000 European Commission report, across 30 European countries the percentage of full professors who are women was on average $15 \%$, with a high of $29.1 \%$ in Romania (cited in Sanders, Willemsen, \& Millar, 2009).

Also, there is evidence that women are typically promoted to full professor later in their careers relative to men (Heijstra, Bjarnason, \& Rafnsdottir, 2015). Women in cognitive psychology would not be expected to be immune to these larger forces. As such, one might predict that women at the senior ranks in cognitive psychology would not be equally visible at a national level relative to men. Of course, earning full professor status itself depends in part on national and international recognition and service, so it is difficult to say that women would not be as highly visible in the field as men because they are less likely to be full professors. They may be less likely to be full professors because they are less visible in the field. There may also be other variables affecting both outcomes.

The early history of women in cognitive/experimental psychology in the United States is also of relevance. There are documented cases where, starting in the late 1800s, women completed all the requirements of a doctoral degree in their field but were not allowed to officially get their degree until many years later, when major research universities finally allowed women entry into doctoral programs (Scarborough \& Furumoto, 1987). Case studies of early psychologists document the barriers of the women this generation faced. For example, Margaret Floy Washburn, a highly productive and visible experimental psychologist who taught at Vassar College, was the first woman in the United States to receive a doctorate in psychology (in 1894) and the second woman ever to be elected to the National Academy of Sciences. Washburn received her doctoral training at Cornell University under the leading exponent of experimental psychology, EB Titchener, but was barred from participating in the annual meetings of "the Experimentalists," an elite group of psychologists that Titchener started in 1904. The group's exclusion of women did not go unremarked, and was the subject of numerous personal appeals and rebukes to Titchener by another pioneering psychologist, Christine Ladd-Franklin (Benjamin, 1986). In a letter to Titchener in 1912, Ladd-Franklin wrote: "I am shocked to know that you are still - at this year excluding women from your meeting of experimental psychologists. It is such a very old-fashioned standpoint" (cited in Benjamin, 1986, p. 132). The Experimentalists admitted women only after Titchener's death in 1927, when the group restructured to form the Society of Experimental Psychologists (SEPs) (described further below). 
Contemporary examples hint at a lingering androcentric bias in cognitive/ experimental psychology. Consider a recent discussion piece in the journal Cognition, coauthored by a group of prominent women researchers in cognitive psychology (Klatzky, Holt, \& Behrmann, 2015) in reference to a previous special issue of the journal in which cognitive psychologists had been invited to provide their assessment of future directions in the field. Klatzky and colleagues remarked:

\begin{abstract}
Upon reading the recent Cognition special issue, titled 'The Changing Face of Cognition' (February 2015), the authors of this discussion felt a collective sense of dismay. Perusing the table of contents, we were struck by the fact that among the 19 authors listed for the 12 articles, only one female author was present. While the substantive context of the issue may persuade us that the face of cognition is changing, it appears that changes in gender distribution are not to be expected. The face of cognitive science will remain unequivocally male. (Klatzky et al., 2015, p. 1).
\end{abstract}

Relatedly, an article appearing in the APS Observer, a publication of the Association for Psychological Science, noted that, relative to men, women in cognitive psychology tend to apply for fewer grants to the National Science Foundation division that funds cognitive research; however, apparently once they do apply they are as likely as men to get their grants funded (Lazar \& Tuller, 2015). As these examples suggest, the initial "collegial exclusion" of women in experimental psychology documented by Scarborough and Furumoto (1987, p. 109) in their history of the first generation of American women psychologists may have had persistent aftereffects in terms of barriers encountered in achieving gender parity in professional visibility.

Our study examined the following questions. Given that there has been, for many years now, gender parity in the awarding of doctorates in cognitive psychology, is it the case that women have reached parity with men in professional visibility in this subfield? That is, do women occupy influential positions as governing board members of professional societies and editors of journals to the same extent as their male counterparts? And are women accorded professional recognition (e.g., Fellow status, lifetime career achievement awards) commensurate with their presumed representation in the discipline?

In addressing these questions, the relevant point of comparison that we are working with, as previously noted, is that within cognitive psychology women comprise approximately half of PhDs awarded in the United States. This number can serve as as liberal reference point as we know that this pattern has held since 1990, meaning that theoretically there could be this many senior female cognitive psychologists in the field. Of course, as mentioned, we know that across the profession of academic psychology at large women in psychology comprise only $34 \%$ of full professor positions and $46 \%$ of associate professor positions in US-based institutions. These numbers could serve as conservative reference points from which to understand women's representation in gatekeeping and leadership positions and receipt of awards. It is worth mentioning, though, that using the proportion of full professors as a benchmark from which to set expectations about gender parity in national 
recognition and leadership could be considered questionable as these markers are themselves necessary for advancement to full professor. But to be clear, we do not predict that women will participate in leadership positions in cognitive psychology in precise step with their proportions at various ranks. We simply note these various points of reference one can use to understand the data.

\section{Professional societies in cognitive psychology in the United States: A brief overview}

To understand women's representation in significant leadership roles in the profession as policymakers, gatekeepers, and recipients of major awards, it is important first to describe the major professional societies in cognitive psychology. While there are more societies than those listed below, the ones we describe here have been in existence the longest, have the largest membership, and explicitly target experimental or cognitive psychologists, cognitive neuroscientists, and cognitive scientists.

\section{Society of Experimental Psychologists}

This initially informal group of about 15 male psychologists known as "the Experimentalists" was established in 1904 by EB Titchener (Benjamin, 2006). Women were elected into the group for the first time only in 1929 when the society officially restructured under its current name. Still operating as an invitation-only society, its membership of around 230 individuals consists of highly distinguished experimental psychologists. Around a third of the society's current members are women. Membership in the society is based on a two-stage process whereby an initial cohort of candidates is reviewed by the governing board who produce a shorter list that is voted on by the membership at large. The society's main activity is to host an annual meeting where members present their research. The Society also administers two senior level awards.

\section{Society for Experimental Psychology and Cognitive Science}

Founded in 1944, and known until last year simply as Division 3 of the APA, this newly renamed society is one of the APA's more than 50 divisions. The APA is the largest professional society of psychologists in the United States, with over 88,000 members at its peak, some years ago. The current membership of the experimental and cognitive science division is close to 1000, which includes around 300 student members. The society publishes a newsletter, allots programming time at the annual convention of the APA, and oversees the Fellow nomination process for its members.

\section{Psychonomic Society}

The Psychonomic Society, established in 1959, has a stated focus of showcasing research in cognitive/experimental psychology. As described on its website, "The Society and its members perform and promote the basic science of behavior 
in areas such as memory, learning, problem solving, action planning, language, and perception that connect with other fields of research." The society hosts an annual meeting in the United States and has recently started an international conference held every three years. It publishes six peer-reviewed journals in cognitive/experimental psychology, with a seventh journal launched in 2016 as the society's first open access journal.

The society's current membership is over 3000 (information about membership breakdown by gender is not available). Until fairly recently, membership was restricted to two categories - members and associate members. One could become a member only by being invited by an existing member and meeting certain requirements, such as having done significant work beyond the doctorate. A strategic plan developed by the society three years ago created a Fellows category, student membership, and emeritus membership. It also created several awards at junior and senior levels.

\section{Association for Psychological Science}

This group was formed in 1988 as the American Psychological Society. It was started by many former members of the APA in response to a perceived need for a separate professional association in psychology that was focused on psychological science rather than on clinical practice, as the APA was perceived to be. The Association of Psychological Science's (APS) membership reached 5000 in the first six months of its formation. Its current membership is over 20,000. Cognitive psychologists represent a substantial number of its members, along with social psychologists and other subfields emphasizing basic research. The APS has a Fellows membership category and members are eligible for several awards at different levels. Although the APS originated in the United States, it has taken concerted actions to expand its international scope, including an international conference held outside the United States, and a name change from the American Psychological Society to the Association for Psychological Science.

\section{The Cognitive Neuroscience Society}

This society was formed in 1994 by six researchers, five of whom were men. It currently has a membership of about 2000 . As stated on its website, "the Cognitive Neuroscience Society (CNS) is committed to the development of mind and brain research aimed at investigating the psychological, computational, and neuroscientific bases of cognition." The CNS sponsors an annual meeting that draws submissions from across the world and it publishes a flagship journal, Journal of Cognitive Neuroscience. The society does not currently have a Fellow designation. It does have two senior level awards and one young investigator award each year.

\section{Women in Cognitive Science}

This society was founded in 2001 by a group of four women to promote women's visibility in the profession. The group was initially given some funds by the 
Psychonomic Society to convene a panel at its annual conference, and it later received a National Science Foundation grant that allowed it to hold panels at other national venues, and to support mentoring efforts. Women in Cognitive Science's (WICS) stated goal is to improve the visibility of women scientists on policymaking and gatekeeping positions and contribute to the professional development of scholars throughout their career. To date, speakers at WICS panels have been senior level women and men faculty, and the issues addressed have been those of particular relevance to junior level scholars. At its 2015 meeting at the Psychonomic Society, WICS organized a successful speed mentoring session for women junior faculty. In addition to its panels, WICS administers an annual conference travel award for a junior scholar and a mentoring award for senior scholars.

A number of other professional associations of relevance to cognitive psychology, such as the Cognitive Science Society, the European Society for Cognitive Psychology, and newer organizations such as the European Cognitive Ageing Society and the Society for the Neurobiology of Language, are not included in our study due to space limitations. As noted earlier, the associations we have chosen to focus on are the largest, oldest, and broadest in their coverage of cognitive psychology.

\section{Indicators of leadership}

\section{Representation on governing board}

The opportunity to serve on the governing board of a professional society provides an important mechanism for shaping policy and for defining what is valued and considered meritorious at the level of an individual's research record and at the level of the field at large. Members are usually elected to serve on the governing board and serve terms that can vary from two to five years.

We describe the governing board composition of the Psychonomic Society as it is the largest autonomous society for cognitive/experimental psychologists and because the governing board's composition in the 50 or so year history of its existence is listed on the society's website, allowing for a look at changes over time.

The composition of the governing board was entirely male from the society's founding in 1959 until 1976, when a woman served on the governing board for the first time. It was not until a decade later that women were elected as chairs in the governing board (in the period 1986-1995 women comprised 16.1\% of the chairs). The percentage of women chairs has not changed in ensuing decades; in the most recent decade (2006-2016), the percentage of women chairs remains at $16.7 \%$, and less than a third of governing board members are women $(26.7 \%)$ (Table 1). This fact may be relevant in understanding other findings we report below.

The society has recently undergone some restructuring and has a more differentiated committee structure (with 12 committees that include appointed members from the society at large as well as from the governing board). The composition of these committees is listed on the society's webpage. The 2016 president-elect of the governing board is a woman. 
Table I. Percent of female members or female chairs of the governing board of the Psychonomic Society over its history.

\begin{tabular}{llc}
\hline & Members & Chair \\
\hline $1960-1974$ & 0 & 0 \\
$1975-1985$ & 15.1 & 0 \\
$1986-1995$ & 29 & 16.1 \\
$1996-2005$ & 31 & 6.9 \\
$2006-2016$ & 26.8 & 16.7 \\
\hline
\end{tabular}

\section{Representation as editors and on editorial boards}

Given the importance of journal article publications in psychology for faculty tenure and promotion decisions, for attracting graduate students, and for establishing one's professional reputation, individuals involved in reviewing journal articles and making decisions about acceptance or rejection arguably serve as important gatekeepers and arbiters of research quality and significance. It is therefore important that they be selected from a broad spectrum of qualified researchers across the discipline. Journal editors are typically identified through a rigorous nominations process and selected by a publications committee appointed by the governing board of a professional society that publishes the journal. Prior editorial experience and general standing in the field are relevant criteria. Editors are typically expected to serve terms ranging from four to six years. Associate editors and members of the editorial board are typically selected by the editor and serve fixed terms, although some societies (e.g., the APA, which publishes several flagship journals in the discipline) periodically issue calls directed at under-represented groups for expressions of interest in serving on journal editorial boards.

To examine the role of gender in journal editorial board composition in cognitive psychology we undertook two searches. We initially searched journals in experimental psychology that have high citation impact scores according to InCites Journal Citation Reports and selected 10 journals from this list that primarily publish empirical articles on cognitive psychology topics (e.g., memory, perception, language, attention, etc.). We excluded journals whose primary focus is on other topics within experimental psychology (e.g., Developmental Psychology), those whose coverage is broader than cognition (e.g., Social Cognitive, \& Affective Neuroscience), or those whose focus is on review articles (e.g., Trends in Cognitive Science), rather than on original, empirical work. The resulting list of journals that met these criteria included: 1) Acta Psychologica, 2) Brain and Cognition, 3) Cognition, 4) Cognitive Psychology, 5) Journal of Experimental Psychology: Human Perception and Performance, 6) Journal of Experimental Psychology: Learning, Memory, and Cognition, 7) Journal of Memory and Language, 8) Journal of Cognitive Neuroscience, 9) Memory \& Cognition, and 10) Psychonomic Bulletin \& Review. The average five-year journal citation impact factor of these journals in 2014 was 4.05, with the impact factor of individual journals ranging 
Table 2. Gender distribution of on an editors, associate editors, and consulting editors on 10 leading cognitive psychology journals and an expanded list of journals covering cognitive topics.

\begin{tabular}{lll}
\hline & Gender & \\
\cline { 2 - 3 } & Male (\%) & Female (\%) \\
\hline Select journal list $(n=10)$ & 100 & 0 \\
Editor-in-chief & 66 & 34 \\
Associate editor & 74 & 26 \\
Consulting editor & & \\
Expanded journal list $(n=60)$ & 80 & 20 \\
Editor-in-chief & 70 & 30 \\
Associate editor & & \\
\hline
\end{tabular}

from 2.31 to 5.72. Two of these journals (numbers 9 and 10) are published by the Psychonomic Society, two are published by the APA (numbers 5 and 6), and one is published by the Cognitive Neuroscience Society (8). We did not include in our survey journals that are open access and available in online only format, such as Frontiers in Psychology, as their editorial boards and review processes are structured quite differently from those of traditional journals.

For each of these 10 journals, we consulted a current issue and identified all editor(s)-in-chief, associate editors, and consulting editors (which included editorial board members listed on the journal's cover page or webpage). We classified each listed person by gender and, where the gender classification could not be performed based on the name alone or on personal knowledge of the researcher, follow-up searches were conducted to locate the researcher's website or other information to confirm their gender identity.

Results from our analyses (see top panel of Table 2) showed that for all 10 journals the position of Editor-in-Chief was held by a male. The absence of females in this role among any of the 10 premier journals in cognitive psychology is surprising as it falls well below what one would expect given the proportion of cognitive $\mathrm{PhDs}$ or of female full professors in psychology. The proportion of associate editors in our list of 10 journals is closer to what one might expect based on the proportion of female full professors in psychology: we found that, on average, $35 \%$ of associate editors are female. ${ }^{1}$ However, the proportion of consulting editors who are female, at $26 \%$, is quite a bit lower than what one might expect, given that consulting editors are often associate professors and sometimes even advanced assistant professors.

One might wonder whether these numbers are representative of the broader set of journals that publish cognitive research. Thus, we examined the editorial board composition of 50 additional journals (for a total of 60 journals) that publish cognitive research. This larger set of journals includes journals that publish reviews, have varying impact factors, and cover other topics in psychology, such as aging, 
development, and emotion, in addition to cognition (Appendix 1). The average fiveyear citation impact for all 60 journals is 2.66, with a range of 21.965 (Trends in Cognitive Sciences) to 0.633 (Journal of Psycholinguistic Research). We found that $80 \%$ of the editors of this expanded list of journals and $70 \%$ of associate editors were male. We did not examine consulting editors for this expanded list of journals (see bottom panel of Table 2). Thus, considering a large number of journals, including those that cover topics in addition to cognition, we found that only a fifth of editorsin-chief and just under a third of associate editors are female.

\section{Indicators of professional recognition}

To examine how women fare in cognitive psychology in terms of receiving recognition for their research accomplishments we examined two kinds of information: the percentage of women who hold the status of Fellow in a professional society and the percentage of women who have been recipients of prestigious honors and recognitions. Although our interest is in describing professional recognition of senior level faculty, we also considered awards directed at junior scholars for comparison. Our analyses were drawn from publicly available information (e.g., websites and newsletters) from the professional societies described earlier.

\section{Fellow designation}

Fellow status is an honor given to only a select subset of the membership of a professional society in recognition of significant research contributions and accomplishments.

Although nomination procedures for applying for Fellow status vary somewhat across the groups surveyed, they typically involve a letter of nomination from a member documenting substantive academic accomplishment of the nominee, a copy of the nominee's curriculum vita, and the endorsement of at least one and usually more than one current Fellow. Self-nominations are typically not allowed.

We examined the gender distribution of current Fellows in all the professional societies that we examined that have this designation, that is, the Society for Experimental Psychology and Cognitive Science (of the APA), the Association for Psychological Science, and the Psychonomic Society. In each case, we report the overall percent of women Fellows, without regard to when Fellow status was conferred, as this information was not consistently available. Furthermore, the count is based on those who are current, dues-paying members of the respective society in which they are a Fellow. Fellows who are listed as retired or who hold emerita/emeritus status are not included in our count.

APA Fellows - Division 3 - Society for Experimental Psychology and Cognitive Science. The APA has two pathways to becoming a Fellow, both of which involve being nominated by a division. If one is not already a Fellow of a division one has to go through a procedure to become what is called an initial Fellow. This requires getting the endorsement of three existing Fellows in the division from which one 
is seeking Fellow status, and by the Fellows Chair of the respective division; the nomination package is subsequently voted on by members of a central governing council of APA. Those who are selected as initial Fellows through this process are eligible to apply to become Fellows in other divisions of the APA; in such cases the decision is made without the governing council's vote. However, the listing of Fellows in the searchable database of the APA membership directory does not distinguish between the two Fellow types. To get an approximate estimate of the number of current Fellows of Division 3 of the APA, we did an online search in the directory listing for Division 3 fellows by member-listed subject areas. This search revealed a total of 145 current Fellows in the combined areas of experimental psychology, cognitive psychology, language processes, memory, and psycholinguistics. Of these, $42(28.96 \%)$, are women.

Psychonomic Society Fellows. Here are the eligibility requirements for seeking Fellow status in the Psychonomic Society, as described on its website:

...Typically, a successful candidate will be at least 3 or more years post-PhD, and will have at least 6 recent research publications in high-quality refereed journals in addition to publications resulting from the Ph.D. Several of these publications must be first-authored. The successful candidate will demonstrate clear evidence of independent scholarship, active engagement in methodologically rigorous and theoretically interesting high level research, and indications of an imminent national/international reputation for excellence in the psychological sciences.

A three person membership committee reviews Fellows nominations twice a year and makes recommendations to the governing board, which votes on each candidate.

We examined the member directory available to us as members of this organization and coded whether the members who were designated as Fellows were male or female. In the majority of cases this could be determined simply by checking the first name. For those cases where the name was gender ambiguous we followed up with an internet search to locate the individual's biographical sketch and/or a picture to confirm their gender. As of May 2015, there are a total of 1244 Fellows in cognitive psychology in the membership of the Psychonomic Society. Excluding 11 who could not be located through an internet search to confirm gender, women comprised $37.86 \%$ of the Fellows $(n=471)$.

APS Fellows. The Association for Psychological Science notes that Fellow status in its society "is typically awarded for one's scientific contributions. However, [it] may also be awarded for exceptional contributions to the field through the development of research opportunities and settings," and candidates for Fellows are expected to have had 10 years of experience after the doctorate. The nomination package involves a letter of nomination and two letters of recommendation from APS members familiar with the nominee's work, at least one of whom is a current Fellow. Each year the association awards about 20 Fellows. The Fellows 
Committee for APS consists of six members. In the past two years, there have been an equal number of men and women on the committee.

The Association for Psychological Science provides a listing of its current Fellows by the name of the researcher, their institutional affiliation, and their area of specialization. From this list, we singled out individuals with Fellow status who describe their primary area as cognitive. We classified each of these by gender. Where the gender classification could not be performed based on the first name we did followup internet searches to locate the researchers' websites or other information to confirm their gender. The few names for which we could not locate the researchers were excluded from our analyses. As of May 2015, 2244 current APS members have been awarded Fellow status. Of these, $17.8 \%$ (or 400) are listed as being primarily cognitive in their research training. Considering only this subgroup and excluding one person for whom gender could not be determined, the percent of women Fellows among all Fellows in cognitive psychology in the APS is $27 \%(n=108)$.

In summary, we see that the percent of women who are Fellows in the three professional societies that have this member designation ranges from $27 \%$ to nearly $38 \%$. What is surprising to us is that the percent of women Fellows in the Psychonomic Society is not higher, given that the criteria require only three years of experience beyond the doctorate and at least six significant publications beyond the dissertation; these criteria could in principle be met by individuals at the rank of advanced assistant professor or associate professor. Of course, ideally one would want to compare the proportion of women Fellows relative to the proportion of women members of the society. We do not have membership distribution by gender for the societies. However, it is worth noting that in a 2006 report commissioned by the Women's Programs Office of the APA, it was stated that, in 2005, $53 \%$ of the 88,124 APA members (excluding student members) were women but only $26 \%$ of Fellows were women (APA Report, 2006).

There could be different reasons for the gender disparity in Fellow status. Women may not consider themselves suitably qualified for this status and may put themselves up for it later in their career than men. Or women may be more hesitant to ask others to nominate them for this designation. Both of these possibilities have been supported in the literature on barriers to women's professional advancement in academia (Valian, 1998).

We next consider gender differences in professional visibility in the form of awards given by professional societies.

\section{Professional awards}

Awards constitute an important mechanism for publicly recognizing what is valued by an organization and thus play a critical role in shaping career trajectories and conferring status and prestige, not only on the individual recipient but also on the institution with which the individual is affiliated. Indeed, "number of academic awards" received by faculty serves as one indicator of quality in rankings of university programs undertaken by independent bodies such as the National Research Council. Thus, apart from the benefits that a professional award brings to an 
individual (in enhancing one's dossier for promotion or tenure, or garnering additional resources), universities are also invested in having their faculty compete for awards as it enhances the university's reputation.

We reasoned that monitoring gender representation for both senior level and junior level awards would be informative. We also report, where available, the award selection process given that such factors as gender composition of award committees and of committee chairs have been shown to affect the characteristics of the pool of awardees (Lincoln, Pincus, Koster, \& Leboy, 2012). Finally, we also paid attention to how the awards were described in the websites of the professional societies to determine if any overt reference is made to issues of gender equity, in light of the literature on implicit bias affecting evaluations of research by men and women (Valian, 1998).

\section{Awards for established scholars}

Society of Experimental Psychologists' Norman Anderson Lifetime Achievement Award. This award, initiated in 2003, is given annually to a single SEP member in the United States or Canada who has shown outstanding achievement over their career life span. Of the 13 recipients to date, only one (7.69\%) has been female (in 2010 neuropsychologist Brenda Milner received the award).

Society of Experimental Psychologists' Howard Crosby Warren Medal. This award, initiated in 1936, is given annually to one or two SEP members who have shown outstanding achievement in the five years preceding the award. It should be noted that, although women were admitted to this society in 1929, there were only a handful of women members for several years and the percent of women members has never been at parity with that of men. Of the 85 recipients of this award since its inception, six $(7.06 \%)$ are women. The first woman to receive this award was Eleanor Gibson, in 1977, and it was not until 1990 that the award next went to a woman (Anne Treisman). The years in which the remaining four women were granted this award were 1994, 2003, 2010, and 2013. The mechanism by which nominations for this award are solicited or reviewed is not stated on the society's website nor is the composition of any award committees.

Psychonomic Society Keynote Address. In 2001, the Psychonomic Society began inviting a keynote speaker to address its annual meeting. Nominations for this speaker are informally solicited from the membership at large and the final decision presumably rests with the governing board. Only a single person is invited to serve as Keynote Speaker each year, and the keynote address is subsequently archived and made available on the society's website for the following year. Of the 15 invited keynote speakers since this award was initiated in 2001 , five $(33.33 \%)$ have been women.

APS William James Fellow Award. This award, administered by the Association for Psychological Science, recognizes APS members "for their lifetime of significant intellectual contributions to the basic science of psychology" (taken from APS 
website). Although not all recipients of this award are cognitive psychologists, we report information about the gender of recipients first from the broad list of recipients. Since the award's inception in 1989, 153 awards have been awarded. Of these, 33 awards have gone to women $(21.57 \%)$ ). In 2015, there were three male recipients and one female (cognitive psychologist) recipient.

A separate analysis of the cognitive awardees showed that of a total of $124 \mathrm{cog}$ nitive psychologist recipients, 21 (or $16.93 \%$ ) of these were women. Unfortunately, there is no comprehensive list of the award recipients by year; thus, it is not possible for us to comment on any patterns over time.

George A. Miller Prize in Cognitive Neuroscience. This award, administered by the Cognitive Neuroscience Society, was established in 1995. As noted on the society's website:

The Prize shall be awarded to the nominee whose career is characterized by distinguished and sustained scholarship and research at the cutting-edge of their discipline and that has in the past, or has the potential in the future, to revolutionize cognitive neuroscience. Extraordinary innovation and high impact on international scientific thinking should be a hallmark of the recipient's work.

The recipient is invited to give an address at the annual meeting of the society. In the 22 years of this award, women have been recipients six times $(27.27 \%)$. When considered over five-year intervals, the prize was awarded to one woman and four men in the first two five-year periods, and to two women and three men in the second two periods. Thus, men comprise the majority of the recipients across all time periods.

Cognitive Neuroscience - Distinguished Career Contribution Award. This award, also given by the Cognitive Neuroscience Society, seeks to honor "senior cognitive neuroscientists for their distinguished career, leadership and mentoring in the field of cognitive neuroscience" (as noted on the website of the CNS). The recipient of this prize gives a lecture at the society's annual meeting. Since 2012, the year the award was initiated, three of the four awardees have been men. The sole female recipient of the award is also the most recent awardee (2015).

\section{Awards for emerging scholars}

We turn next to awards directed at emerging scholars in the professional societies we examined. Of the four awards of this type, three are administered by the Psychonomic Society and one by the APS.

Psychonomic Society Early Career Award. This award, initiated in 2012, is intended for "young scientists who have made significant contributions to scientific psychology early in their careers. The purpose of the awards is to raise the visibility of our science and of our very best young scientists within the field, within the awardees' institutions, in the press, and in the larger community" (taken from the website, http://www.psychonomic.org/early-career-awards). No more than four awards are 
given each year. The governing board designates one member from the Board to chair the awards committee, and additional members of the society, "reflecting the areas of research that are characteristic of the society", to serve on the committee. The awards committee reviews nominations and makes recommendations to the governing board, which then votes on whether to endorse the recommendations.

Of the 16 individuals who have received this award through 2015, six $(37.5 \%)$ have been women. In terms of the gender breakdown by year, the number of female awardees each year, out of a total of four awardees per year, was one, zero, three, and two, in the years 2012-2015, respectively.

Clifford T. Morgan Best Article Award. This award by the Psychonomic Society was initiated in 2013. It is given to the primary author of the best journal article published each year in a particular journal. The choice is made by the editor of each of the journals published by the Society. To date there have been 18 articles selected and a total of 19 awardees (six each in 2013 and 2014 and seven in 2015, including one article with two awardees). Of the 19 awardees to date, $15(78.9 \%)$ have been male. Of the four females given this award three were in the most recent, 2015, cohort.

Member-Select Award. This award administered by the Psychonomic Society recognizes the top 10 abstracts submitted to the annual conference, by eligible members who have indicated an interest in being considered for this award. The 1000-word abstracts are reviewed by members of the Program Committee. To be eligible for the award, submitters must be dues-paying members who are not student members, Fellows or emeritus members. Since the award was initiated in 2013, a total of 29 Member-Select Awards have been conferred; of these, women comprise 15, or slightly over half of the awardees, $(51.72 \%)$. Furthermore, the distribution of male and female awardees has been fairly even in each year of this award.

APS Janet Taylor Spence Award for early transformative career contributions. This annual award, administered by the Association for Psychological Science since 2010, recognizes at least five APS members per year who are no more than eight years post-PhD for their transformative contributions. As noted on the APS website, transformative research contributions may include "the establishment of new approaches or paradigms within a field of psychology, or the development or advancement of research that cuts across fields of psychological science." Of the total of 35 awards that have been given since 2010, 16 (or $45.71 \%$ ) have been awarded to women. The gender distribution has been roughly even across the years. The current composition of the Spence Award committee, also noted on the APS website, includes seven women and one man, and the committee is chaired by a woman.

Table 3 provides a summary of the percent of women recipients of professional honors averaged across the different awards discussed above. Setting aside two awards not reviewed above - a WICS award that targets women and a Cognitive Neuroscience Young Investigator Award that explicitly targets one man and one woman awardee each year - we see that an average of $41.41 \%$ of awards directed at junior scholars have been awarded to women, whereas only $14.11 \%$ of awards 
Table 3. Total number and percent female Fellows, award recipients, and invited keynote speakers in major professional societies in cognitive psychology (based on aggregated data reported in body of paper).

\begin{tabular}{lrl}
\hline & Total number & Female (\%) \\
\hline APA, APS, and Psychonomics Fellows & 1789 & 34.71 \\
Psychonomics keynote speaker & 15 & 33.33 \\
Senior Level Society Awards & 248 & $14.1 \mathrm{I}$ \\
Junior Level Society Awards & 99 & $41.4 \mathrm{I}$ \\
\hline
\end{tabular}

directed at senior scholars have been awarded to women. The percent of women recipients of awards directed at junior scholars ranged from $38 \%$ to slightly over $51 \%$. This suggests either that the gender gap is indeed less pronounced for junior scholars or that review committees are more conscious about achieving gender parity at this level.

\section{Discussion}

An androcentric bias has characterized mainstream psychology's construction of women as deviant and men as the generalizable norm (Shields, 1975). Our study examined whether a male bias may be said to operate in leadership, gate-keeping, and professional recognition in the field of cognitive psychology.

Shields's (1975) article demonstrated how psychological research has been used to justify prevailing myths, such as how differences between men and women's behavior may be "explained" by differences in their brain structure. A prevailing belief (which some may call a myth) that undergirds our own study of gender differences in professional visibility in cognitive psychology is the belief that science functions as a meritocracy, that is, a system that recognizes and rewards people on the basis of their ability and research performance. In a true meritocracy characteristics such as a person's age or gender should be irrelevant in the distribution of rewards and other markers of success, for what matters most is the quality and quantity of the research.

While we did not examine how women fare in terms of their quality and quantity of research relative to men, we did examine how they fare in terms of their professional visibility at the senior level. This issue has been under-studied (Rosser, 2014). Our findings document disparities in professional visibility on a range of indicators. Although it is possible that women are gradually assuming more positions of leadership (e.g., serving on governing boards of professional societies, and as editors), their current representation in these positions is still far lower than what one might expect given their estimated representation in senior ranks of the professoriate. That is, with $34 \%$ as an approximate benchmark for women full professors in psychology, our analysis showed that women comprise only $20 \%$ of journal editors in cognitive psychology, and that the percentage of women 
recipients of lifetime career achievement awards in this subfield is lower still (less than 15\%). However, the percent of women Fellows approximates what one might expect given the benchmark. Thus, with the exception of Fellow status, women at the senior ranks appear to be under-represented, particularly among recipients of lifetime career achievement awards bestowed by professional societies. While the situation is somewhat better for junior level awardees, women are still not receiving awards to the same degree as men at this level.

It is noteworthy that the language in which the awards at each level are described is avowedly gender-neutral, for example, "best young scientists within the field" or "outstanding achievement," and nowhere in the website descriptions is there any explicit recognition of an attempt to address gender disparities (or even to acknowledge that they may exist). Yet many of the awards themselves are named after prominent men in the profession: William James, George Miller, and Norman Anderson, and the Howard Crosby Warren Medal, named after the founder of the SEP, or the Clifford T Morgan award, named after the founder of the Psychonomic Society. Only one award bears the name of a prominent woman, Janet Taylor Spence. It is possible that the predominance of awards named after men in the profession works against the gender-neutral descriptions of the awards and may have an unintended effect of making women feel less included or that they are less deserving of the award. One solution to this may be to create new awards bearing a woman's name, or to add a woman's name to an award that bears a man's name. This would send a signal that the award is truly inclusive, and also that there are women scientists worthy of being recognized by having their name on an award. Yet what is interesting is that a majority of the named awards were created (and named) fairly recently. Thus, sensitivity to the gendered nature of the award title seems not to have been a concern. This inattention to the potential impact of the predominantly male titles of the awards may be an example of the males-as-generalizable-norm. Furthermore, it is interesting that the one award named after a woman psychologist (Janet Spence) is directed at early career scholars. Thus, there is no named award in any of the professional societies at the senior level named after a woman researcher.

There are hints of a possible sensitivity to issues of gender equity in the award selection process in some cases. As one example, for the 2015 cohort of Psychonomic Society Fellows, which showed the highest percent of female Fellows to date $(42.9 \%)$, the three person membership committee listed on the website as being in charge of reviewing the applications and making recommendations to the governing board consisted entirely of women. Similarly, for the Janet Taylor Spence Early Career Award, the review committee is chaired by a woman and consists predominantly of women. As another example of a possible change in awareness of a gender gap, we note that in the first year of the Psychonomic Society Early Career award, all four recipients were male, in the second year one of the four was male and in the third year there were two males and two females. At the same time, when the award designation is to be made by journal editors of the six Psychonomic Society journals (the majority of whom are male), the percent of women awardees was found to be markedly lower than that of other junior level 
awards by the Psychonomic Society. We do not know what specific factors may account for these differences.

Taken together, our findings suggest that, in the field of cognitive psychology, men continue to hold the most influential positions (as editors-in-chief of the leading journals) and have been the recipients of senior-level awards at a level that is greater than their representation in the field. Even at more junior levels, there is an over-representation of men among editorial board members and among recipients of early career awards.

A gender gap in promotion and recognition in academia is not unique to cognitive psychology, of course. Similar findings have been reported for a variety of other academic disciplines. Structural factors such as gender disparities in resource allocation or rewards (Duch et al., 2012) likely contribute to a gender gap in professional visibility. Psychological factors such as gender differences in self-confidence (Young, 2011) or unconscious gender biases held by both men and women that adversely impact women's advancement (e.g., Valian, 1998), or selective biases against research evidence of a gender bias (Handley, Brown, Moss-Racusin, \& Smith, 2015), are also relevant. Determining the relative contribution of different potential sources of observed gender gaps is a matter of continued debate (e.g., Ceci, Ginther, Kahn, \& Williams, 2014; Geraci, Balsis, \& Busch, 2015). This debate is important as it can inform the kinds of interventions that could help close the gaps.

Our study has some limitations that need to be acknowledged and addressed in further research. One is that our summary of editorial board gender composition is based on a current snapshot. We have not tracked this information over time and thus we cannot say whether the current profile, such as it is, represents an improvement over previous years (although a previous analysis done in 1985, cited in Cundiff, 2012, and not confined to cognitive psychology, found that at that time women comprised $13 \%$ of editors of APA journals).

Another limitation of our analysis is that we have focused on the category of gender without considering how this category intersects with other social dimensions along which individuals differ, such as class and race/ethnicity. An intersectional analysis is needed to examine how professional (in)visibility related to gender interacts with that related to race (e.g., Vaid, 2015). Furthermore, as noted by Walsh (2015, p. 62), an intersectional perspective to knowledge production in science would bring attention to "the existence of biases born of privilege, and the importance of marginalised experience in understanding certain phenomena."

A third limitation of our study is that we do not specifically address the growing importance of cognitive neuroscience, which has transformed the professional landscape, affecting how research is conducted not only in cognitive psychology but in several other areas of psychology, over the past 20 years. An increasing number of faculty positions are advertised in cognitive (or social, or affective) neuroscience, and hiring faculty in these areas requires considerable investments on the part of universities to cover the additional costs new faculty in these areas require, for the hiring of post-docs, access to imaging facilities, and grant-writing support. A host of new issues arise when considering how female compared to male 
cognitive neuroimaging faculty may negotiate resources and form successful collaborations with faculty in other, traditionally male-dominated fields, such as biology, computer science, and physics.

Our finding that women are under-represented in positions of leadership (editors-in-chief, or recipients of distinguished career awards) may beg the question of whether there are gender differences in productivity that could account for the disparities observed. Perhaps women in cognitive psychology simply are less productive and therefore do not garner professional recognition to the same degree as their male counterparts (see Cho, Tse, \& Neely, 2012, for an analysis of the top cited publications from 1950 to 2004 in cognitive psychology). Because we do not have current data on gender differences in publication output, quality or citation impact among cognitive psychologists, this question cannot fully be addressed. Yet even if such data existed for cognitive psychology (see Konig, Fell, Kellnhofer, \& Schui, 2015, for such an analysis in industrial/organizational psychology), one would still need to ask whether or how proxy indicators of productivity may themselves be gendered; for example, quantity is often valued over quality of research and some research suggests that men tend to publish more but women's publications at a given rate of productivity tend to draw more citations. Furthermore, metrics of productivity do not factor in gender differences in time spent on teaching, mentoring, or service activities. Gender has also been shown to intersect with other known factors that contribute to citation impact and other metrics of productivity, such as a researcher's co-author networks (see Krefting, 2003, for further discussion).

\section{Conclusion}

Our findings show that whatever progress women have made in terms of achieving parity with men in earning $\mathrm{PhDs}$ in cognitive psychology has not resulted in parity in professional visibility. We found that there are only male editors-in-chief in our sample of 10 premier cognitive psychology journals. In the extended list of 60 leading cognitive journals, the vast majority $(80 \%)$ of the main editors and approximately two-thirds of the editorial board members are male. The vast majority of senior level award recipients are male as well. Approximately two-thirds of the Fellows in the various professional societies are male. Looking at the different types of awards, the data show that awards at early stages of a scholar's career tend to show less gender disparity than those at later stages. Finally, our observations suggest that although progress in achieving gender parity in governing board gender composition continues to be slow, when there is gender parity in award committee composition or in governing board membership women appear to fare better than when there is more female representation in these committees, consistent with previous work on this issue (e.g., Lincoln et al., 2012).

What are the implications of these data? Certainly one could hypothesize that the greater numbers of males than females in leadership positions, and particularly on editorial boards, might mean that males have a larger role in shaping the science and in determining whose research and which research findings are considered 
notable or meritorious. Researchers and theorists note that science is always done in context - and that the social context can influence both the topics of science and also the make-up of that science (Burman, 1994, 2008).

In a recent special issue of Feminism \& Psychology devoted to Burman's ideas about the relationship between the social context and science, researchers suggested that cognitive theories may be influenced by researchers' backgrounds and gender. For example, it was suggested that some theories, such as theories of executive functioning, reflect prototypical Western masculinized concepts of speed, efficiency, and control (Miller \& Scholnick, 2015). The authors suggested that the terms and theories of executive functioning and cognitive control reflect a masculine social context. For example, they note that the term, "executive" (a title that still overwhelmingly describes positions in organizations held by males) is used to refer to control processes and that many models focus on this competitive corporate model when applying metaphors to understanding and describing cognitive processes (rather than, say, focusing on facilitating or coordinating functions that imply collaboration, which is typically emphasized by feminists and by other cultures). In fact, Miller and Scholnick suggest that these competitive and compartmentalized models of cognitive control may be insufficient and outdated and that we may be better served by using other approaches to understanding cognition. Also, research on executive functioning tends to emphasize the biological underpinnings of executive functioning and pathologize diversity. Noting this implicit bias, Gernsbacher (2007, 2013) encourages the use of the phrase "neural diversity" to understand differences in brain structure underlying behavior.

Also, Miller and Scholnick argue that theories of executive functioning often de-emphasize context which, they argue, reflects a masculine and narrow view of cognition. Of course, there are many theoretical advances to be made by considering people's social and emotional contexts. In the field of cognitive aging, for example, we know now that older adults often show worse executive functioning than younger adults on many standard cognitive tasks, yet they are often highly skilled in using control processes to reach social and emotional goals (e.g., Mather \& Knight, 2005).

Some might wonder whether the history of cognitive psychology may contribute to the lower levels of women in leadership positions in cognitive psychology. That is, because cognitive psychology developed out of stereotypically masculine disciplines and interests, such as computer science and military science, it may not attract as many women as men to it. We think that this is an unlikely explanation for gender differences in leadership roles and recognition, as there are equal numbers of women and men receiving $\mathrm{PhDs}$ in cognitive or experimental psychology, suggesting that the levels of interest in the topic are not vastly different. But, it is possible that the nature of the science may somehow discourage women's participation at the highest levels of the field.

The greater representation of males than females in leadership roles also has implications for the individual scientists, in terms of scientific achievement and compensation. We know that women are paid less than males at all ranks (American Association of University Professors, 2014), and that they are 
more slowly promoted and less likely to be promoted than males (Heijstra et al., 2015).

There are probably many factors that contribute to the finding that women are less represented then men in highly visible leadership roles in cognitive psychology. We know that research by women is not as valued as is research by males (Knobloch-Westerwick, Glynn, \& Huge, 2013; Wenneras \& Wold, 1997), and that women are less likely to be seen as competent by both male and female scientists (Moss-Racusin, Dovidio, Brescoll, Graham, \& Handelsman, 2012). It is also possible that women do not have as much time or as many resources as males to take on these "extra" national service roles. There is evidence that women shoulder more family care responsibilities than men and that they carry a greater department service load than men, particularly at the associate professor rank, which may adversely affect research productivity and advancement (Misra, Hicke, Lundquist, Holmes, \& Agiomavritis, 2011; Xie \& Shauman, 2003). It is also possible that, relative to their male counterparts, female cognitive psychologists are less interested in these roles. For example, reviewing for journals and participating in committee work can be unpleasant jobs, and so women may recognize the downside to this type of work. However, this hypothesis is weakened by data mentioned earlier showing that women do take on significant service roles, at least at the local level (Misra et al., 2011). Yet the demands of journal editorships (which carry six year terms in the case of APA journals in experimental psychology, and a requirement to review 90 manuscripts a year) may be viewed as onerous by women with caregiving or other responsibilities that their male counterparts may not have.

Why are women not receiving as many awards as men? Again, there are probably several explanations for this finding. Research has documented, for example, that women are less likely to put themselves up for awards and prizes; moreover, as already mentioned, composition of award selection committees has been found to influence the gender composition of the applicant pool. It has also been found that women tend to be over-represented in certain award categories, such as those specifically targeting women in mentor roles (Lincoln et al., 2012). Experimental evidence shows that people's beliefs about men and women's capabilities influence self-assessments of abilities (Correll, 2001), which may make women less likely to promote themselves and ask for nominations from others, compared to men of equal ability (Fiorentine, 1987; Rudman, 1998). Also, letters of recommendation for awards differ for males and females (McCarthy \& Goffin, 2001; Trix \& Psenka, 2003), and these differences may disadvantage women from receiving awards. For example, research shows that males are often characterized as superb, outstanding, and remarkable (Trix \& Psenka, 2003). An examination (Madera, Hebl, \& Martin, 2009) of more than 600 letters of recommendation for male and female applicants for faculty positions in psychology at research-intensive universities showed similar findings - letters for female applicants were more likely to include "communal" attributes, such as affectionate, warm, kind, and nurturing. Letters for male applicants, on the other hand, were more likely to include "agentic" terms, such as ambitious, dominant and self-confident, and these effects occurred while controlling for a 
variety of factors, such as number of publication, postdoctoral years, and honors. Further, Madera and colleagues showed that these communal characteristics had a negative association with hireability ratings. It is possible that these sorts of characteristics also have a negative association with receipt of awards. Again, it is also possible that women are less interested in receiving awards for their work than are men, but we do not know of research demonstrating this.

Ultimately, our data cannot isolate the specific reasons for the lack of gender parity in editorships and awards. We can simply document the proportions of women in senior positions in the field and the proportions of women receiving awards. The hope is that documenting these data in cognitive psychology will draw attention to the issue and increase sensitivity to a need for greater inclusion of women in positions of leadership and visibility. Academic departments and professional societies alike will need to take more concerted efforts to encourage women to be nominated for awards at senior levels.

We note that several institutional policies and programs, such as the National Science Foundation's ADVANCE program, exist to encourage women and remove barriers to their participation in Science, Technology, Engineering, and Math (STEM) fields and to achieving national visibility. Also, WICS has created mentoring programs and awards specifically designed to enhance the support and visibility of women in cognitive science. At the same time, most such efforts to date have focused on junior women or else have included senior women only as role models or mentors for junior women faculty, rather than addressing the needs of senior women as such.

As Rosser (2014) notes, a majority of senior tenured faculty, including women, are delaying retirement and choosing to continue teaching and conducting research. By not recognizing and acting on the issues senior women psychologists face, she notes, there is a risk of "undercutting the productivity and professional contributions built over a life-time of these women, who earlier in their careers, overcame many obstacles to become successful" (Rosser, 2014, p. 239). One can only hope that cognitive psychology will see the benefit to the profession of taking this issue seriously.

\section{Acknowledgements}

We thank three founding members of Women in Cognitive Science and other senior women psychologists for meeting with us during the 2015 Psychonomics Society conference to discuss issues related to this project. Noemi Garcia assisted in coding the data, and Diana Ramirez of the Evans Library at Texas A\&M University provided assistance in identifying relevant databases. We are grateful to members of the Women's and Gender Studies Program, the Office for Diversity, and the Diversity Science Cluster at Texas A\&M University, and Drs Loraine K. Obler, Virginia Valian, and Michelle Fine of the CUNY Graduate Center for valuable discussions. Finally, we appreciate the detailed and helpful comments of the three reviewers.

\section{Declaration of conflicting interests}

The author(s) declared no potential conflicts of interest with respect to the research, authorship, and/or publication of this article. 


\section{Funding}

The author(s) disclosed receipt of the following financial support for the research, authorship, and/or publication of this article: This project benefited from funding support to the first author from Texas A\&M's College of Liberal Arts IIDEAS Grant Program and the ADVANCE Center's Minigrant Program, and from faculty development leave support.

\section{Note}

1. For the journal Brain and Cognition, we included both Associate Editors and Action Editors in our analysis of Associate Editors.

\section{References}

American Association of University Professors. (2014). Losing focus: The AAUP annual report on the economic status of the profession 2013-2014. Academe, the magazine of the American Association of University Professors, 100, 4-38.

American Psychological Association Center for Workforce Studies. (2014). How is the gender composition of faculty in graduate psychology departments changing? News from the APA's Center for Workforce Studies, 45, 11. Washington, DC.

American Psychological Association Women s Program's Office. (2006). Women in the American Psychological Association.

Ansara, Y. G., \& Hegarty, P. (2014). Methodologies of misgendering: Recommendations for reducing cisgendering in psychological research. Feminism \& Psychology, 24, 259-270.

Benjamin, L. T. (2006). Chapter 10: Titchener's experimentalists: No women allowed. In $A$ history of psychology in letters (2nd ed, pp. 125-138). Malden, MA: Blackwell.

Braun, V. (2000). Heterosexism in focus group research: Collusion and challenge. Feminism \& Psychology, 10, 133-140.

Burman, E. (1994). Deconstructing developmental psychology. London, UK: Routledge.

Burman, E. (2008). Deconstructing developmental psychology (2nd ed.). London, UK: Brunner-Routledge.

Ceci, S. J., Ginther, D. K., Kahn, S., \& Williams, W. M. (2014). Women in academic science: A changing landscape. Psychological Science in the Public Interest, 15, 75-141.

Cho, K. W., Tse, C.-S., \& Neely, J. (2012). Citation rates for experimental psychology articles published between 1950 and 2004: Top-cited articles in behavioral cognitive psychology. Memory \& Cognition, 40, 1132-1161.

Cikara, M., Rudman, L., \& Fiske, S. (2012). Dearth by a thousand cuts? Accounting for gender differences in top-ranked publication rates in social psychology. Journal of Social Issues, 68, 263-285.

Correll, S. (2001). Gender and the career choice process: The role of biased self-assessments. American Journal of Sociology, 106, 1691-1730.

Cundiff, J. L. (2012). Is mainstream psychological research "womanless" and "raceless"? An updated analysis. Sex Roles, 67, 158-173.

Duch, J., Zeng, X. H. T., Sales-Pardo, M., Radicchi, F., Otis, S., \& Woodruff, T. (2012). The possible role of resource requirements and academic career-choice risk on gender differences in publication rate and impact. PLoS ONE, 7, e51332.

Eagly, A. H., Eaton, A., Rose, S., Riger, S., \& McHugh, M. (2012). Feminism and psychology: Analysis of a half century of research on women and gender. American Psychologist, 67, 211-230. 
Fine, M., \& Gordon, S. M. (1989). Feminist transformations of/despite psychology. In M. Crawford \& M. Gentry (Eds.), Gender and thought (pp. 146-174). New York, NY: Springer-Verlag.

Fiorentine, R. (1987). Men, women, and the premed persistence gap: A normative alternatives approach. American Journal of Sociology, 5, 1118-1139.

Geraci, L., Balsis, S., \& Busch, A. J. (2015). Gender and the h index in psychology. Scientometrics, 105, 2023-2034.

Gernsbacher, M. A. (2007). Neural diversity. APS Observer, 20(5), 15.

Gernsbacher, M. A. (2013). Brain differences are not always deficits. APS Observer, 26, 13-14.

Handley, I. M., Brown, E. R., Moss-Racusin, C. A., \& Smith, J. L. (2015). Quality of evidence revealing subtle gender biases in science is in the eye of the beholder. Proceedings of the National Academy of Science, 112, 13201-13206.

Heijstra, T., Bjarnason, T., \& Rafnsdottir, G. L. (2015). Predictors of gender inequalities in the rank of full professor. Scandinavian Journal of Educational Research, 59, 214-230.

Kite, M., Felipe Russo, N., Brehm, S., Fouad, N., Hall, C., Hyde, J., \& Keita, G. (2001). Women psychologists in academe: Mixed progress, unwarranted complacency. American Psychologist, 56, 1080-1098.

Klatzky, R., Holt, L., \& Behrmann, M. (2015). The representation of women in cognition. Cognition, 141, 170-171.

Konig, C., Fell, C., Kellnhofer, L., \& Schui, G. (2015). Are there gender differences among researchers from industrial/organizational psychology? Scientometrics, 105, 1931-1952.

Knobloch-Westerwick, S., Glynn, C. J., \& Huge, M. (2013). The Matilda Effect in science communication an experiment on gender bias in publication quality perceptions and collaboration interest. Science Communication, 35(5), 603-625.

Krefting, L. (2003). Intertwined discourses of merit and gender: Evidence from academic employment in the USA. Gender, Work and Organization, 10, 262-278.

Lazar, V., \& Tuller, B. (2015). Is there a gender gap in the Perception, Action, and Cognition Program at NSF? The APS Observer, 28 May/June.

Lincoln, A. E., Pincus, S., Koster, J., \& LeBoy, P. (2012). The Matilda effect in science: Awards and prizes in the U.S., 1990s and 2000s. Social Studies of Science, 42, 307-320.

Longino, H. (1990). Science as social knowledge: Values and objectivity in scientific inquiry. Princeton, NJ: Princeton University Press.

Madera, J. M., Hebl, M. R., \& Martin, R. C. (2009). Gender and letters of recommendation for academia: Agentic and communal differences. Journal of Applied Psychology, 94, 1591-1599.

Mather, M., \& Knight, M. (2005). Goal-directed memory: The role of cognitive control in older adults' emotional memory. Psychology and Aging, 20, 554-570.

McCarthy, J. M., \& Goffin, R. D. (2001). Improving the validity of letters of recommendation: An investigation of three standardized reference forms. Military Psychology, 13, 199-222.

Miller, D., \& Halpern, D. (2014). The new science of cognitive sex differences. Trends in Cognitive Science, 18, 37-45.

Miller, P. H., \& Scholnick, E. K. (2015). Feminist theory and contemporary developmental psychology: The case of children's executive function. Feminism \& Psychology, 25, 266-283.

Misra, J., Hicke, Lundquist, J., Holmes, E., \& Agiomavritis, S. (2011). The ivory ceiling of service work. Academe, the Magazine of the American Association of University Professors, 97.

Monroe, K. R., \& Chiu, W. (2010). Gender equality in the academy: The pipeline problem. Perspectives on Politics, April, 303-308.

Morawski, J. G. (2004). White experimenters, white blood, and other white conditions. Locating the psychologist's race. In M. Fine, L. Weis, L. Powell Pruitt, \& A. Burns (Eds.), Off white: Readings on race, power, and society (2nd ed.). London: Routledge. 
Morawski, J. G., \& Agronick, G. (1991). A restive legacy: The history of feminist work in experimental and cognitive psychology. Psychology of Women Quarterly, 15, 567-579.

Moss-Racusin, C. A., Dovidio, J. F., Brescoll, V. L., Graham, M. J., \& Handelsman, J. (2012). Science faculty's subtle gender biases favor male students. Proceedings of the National Academy of Sciences, 109(41), 16474-16479.

Musser, A. J. (2015). Specimen days: Diversity, labor, and the university. Feminist Formations, 27, 1-20.

Riger, S. (1992). Epistemological debates, feminist voices: Science, social values, and the study of women. American Psychologist, 47, 730-740.

Rosser, S. V. (2014). Senior compared to junior women academic scientists: Similar or different needs? Gender Transformations in the Academy: Advances in Gender Research, 19, 221-241.

Rudman, L. A. (1998). Self promotion as a risk factor for women: The costs and benefits of counter-stereotypical impression management. Journal of Personality and Social Psychology, 74, 629-645.

Salters, P., \& Adams, G. (2013). Toward a critical race psychology. Social and Personality Psychology Compass, 7, 781-793.

Sanders, K., Willemsen, T., \& Millar, C. (2009). Views from above the glass ceiling: Does the academic environment influence women professors' careers and experiences? Sex Roles, $60,301-312$.

Scarborough, E., \& Furumoto, L. (1987). Untold lives: The first generation of American women psychologists. New York, NY: Columbia University Press.

Shields, S. A. (1975). Functionalism, Darwinism, and the psychology of women. American Psychologist, 30, 739-754.

Shields, S. A. (2012). Gender and emotion: What we think we know, what we need to know, and why it matters? Psychology of Women Quarterly, 37, 423-435.

Shields, S. A., \& Dicicco, E. C. (2011). The social psychology of sex and gender: From gender differences to doing gender. Psychology of Women Quarterly, 35, 491-499.

Trix, F., \& Psenka, C. (2003). Exploring the color of glass: Letters of recommendation for female and male medical faculty. Discourse and Society, 14, 191-220.

Vaid, J. (2015, March). Gender and race in academic psychology: Moving beyond the presence of an absence. Poster presented at Women's Research on Women Symposium, Texas A\&M University, College Station, TX.

Vaid, J., \& Meuter, R. (2016). Not through a glass darkly: Refocusing the psycholinguistic study of bilingualism through a 'bivocal' lens. In V. Cook \& L. Wei (Eds.), Cambridge handbook of linguistic multicompetence. Cambridge, UK: Cambridge University Press.

Valian, V. (1998). Why so slow? The advancement of women. Cambridge, MA: MIT Press.

Walsh, R. J. (2015). 'Objectivity' and intersectionality: How intersectional feminism could utilise identity and experience as a dialectical weapon of liberation within academia. Feminism \& Psychology, 25, 61-66.

Weisstein, N. (1993). Power, resistance, and science; A call for a revitalized feminist psychology. Feminism and Psychology, 3, 239-245.

Wenneras, C. \& Wold, A. (1997). Nepotism and sexism in peer-review. Commentary. Nature, 22, 341-343.

Xie, Y., \& Shauman, K. A. (2003). Women in science: Career processes and outcomes. Cambridge, MA: Harvard University Press.

Young, V. (2011). The secret thoughts of successful women: Why capable people suffer from the impostor syndrome and how to thrive in spite of it. New York, NY: Random House. 


\section{Author Biographies}

Jyotsna Vaid is Professor of Psychology and Women's and Gender Studies, and is currently the Director of Organizational Development, Research, and Equity at the Office for Diversity at Texas A\&M University. Her research interests include bilingualism, creative thought, and the social construction of merit in academia. She has published two edited books (Language processing in bilinguals: Psycholinguistic and neuropsychological perspectives, and Creative thought: An investigation of conceptual structures and processes) and over 100 articles and chapters. Vaid is a Fellow of the Psychonomic Society and of the Association for Psychological Science and a founding Editor of Writing Systems Research. She serves on the editorial boards of Laterality: Asymmetries of Body, Brain, and Cognition, the Journal of Neurolinguistics, and Frontiers in Psychology (Cognition section).

Lisa Geraci is Associate Professor of Psychology and Head of the Cognition and Cognition Neuroscience Program at Texas A\&M University. Her research interests include memory and aging, metacognition, learning and education, self-perceptions of aging, and gender and academia. Geraci's research has been supported by grants from the National Institute on Aging and the National Science Foundation. She has published over 40 articles and chapters on memory and cognition. She is a Fellow of the Psychonomic Society and of the Association of Psychological Science and serves on the editorial boards of Journal of Memory and Language and Experimental Aging Research.

\section{Appendix I}

\section{Journals Consulted for Editorial Board Analysis}

Acta Psychologica

Advances in Cognitive Psychology

Aging Neuropsychology and Cognition

Applied Cognitive Psychology

Applied Psycholinguistics

Attention Perception \& Psychophysics

Behavior Research Methods

Bilingualism-Language and Cognition

Brain and Cognition

Brain and Language

Canadian Journal of Experimental Psychology

Cognition

Cognition \& Emotion

Cognition and Instruction

Cognitive, Affective, \& Behavioral Neuroscience

Cognitive Development

Cognitive Neuropsychology

Cognitive Processing 
Cognitive Psychology

Cognitive Science

Cognitive Systems Research

Computers in Human Behavior

Consciousness and Cognition

Discourse Processes

Experimental Psychology

Human Movement Science

i-Perception

Journal of Applied Research on Memory and Cognition

Journal of Child Language

Journal of Cognition and Development

Journal of Cognitive Neuroscience

Journal of Cognitive Psychology

Journal of Experimental Psychology: Animal Learning and Cognition

Journal of Experimental Psychology: General

Journal of Experimental Psychology: Human Perception and Performance

Journal of Experimental Psychology: Learning, Memory, and Cognition

Journal of Memory and Language

Journal of Motor Behavior

Journal of Neurolinguistics

Journal of Psycholinguistics Research

Language and Cognitive Processes

Laterality

Learning \& Behavior

Learning and Motivation

Memory

Memory \& Cognition

Neuropsychologia

Perception

Psychological Research-Psychologische Forschung

Psychology of Learning and Motivation

Psychonomic Bulletin \& Review

Quarterly Journal of Experimental Psychology

Seeing and Perceiving

Social Cognitive and Affective Neuroscience

Spatial Cognition and Computation

Thinking \& Reasoning

Topics in Cognitive Science

Trends in Cognitive Sciences

Visual Cognition

Wiley Interdisciplinary Reviews-Cognitive Science 